\title{
Innovative changes in the cylinder liners surface shaping methods
}

\author{
Jozef Gruszka ${ }^{1, *}$ \\ ${ }^{1}$ Poznan University of Technology, Faculty of Engineering Management, ul. Strzelecka 11, 60-965 Poznan, Poland
}

\begin{abstract}
The main directions of changes in new internal combustion engine designs are determined not only by legislation on the toxic components emission in the exhaust gases, but also by the changes resulting from technological development, which are the results of research and development activities. One of the basic systems that has undergone intensive development recently is the piston-rings-cylinder (PRC) node. This article contains an original analysis of the direction of changes in cylinder surface shaping in terms of the cylinder's main functional features in the PRC system (the casting material and the opening surface topography after the finishing process). The results of the research on cast iron materials for cylinder liner castings with strength of $R_{m}>300 \mathrm{MPa}$ were analyzed based on the centrifugal casting method and their finishing stage in the finishing process meeting the criteria for reduction of oil consumption and particle emissions for new HDD type engine designs. The author also points to innovations in surface structure metrology based on new 3D optical measurement methods and the quality rating method by Mercedes company.
\end{abstract}

\section{Introduction}

In the construction of each combustion engine, the central position is occupied by a piston-cylinder system, often called the piston-ring-cylinder system (abbreviated as PRC, Fig. 1). In the operating range of this system, the basic processes of the of thermodynamic conversion of combustion energy of a gas into a reciprocating motion force take place, which are fundamental for the engine operation. In terms of working loads the PRC is the most complex and heavily loaded tribological system in the internal combustion engine $[1,2]$. Its individual components: the piston, the piston rings and the cylinder sleeve form a movement pattern between each other which, in tribological terms, each constitute separate systems.. Analysis of individual tribological systems (cylinder liner-piston, piston-piston rings, piston ringscylinder liner, cylinder-engine block) based on [3-5] as well as own investigations results [6-10] seem to indicate that the piston rings-cylinder liner system has a dominant functional and tribological significance in the PRC system. From the tribological properties of cylinder liners and piston rings, the material and its mechanical properties are first listed (strength, hardness), then its structure and chemical composition. For cylinder liners, errors in the macroscopic shape of the opening are formed (roundness, straightness or coaxiality) and micro geometry of the opening (the shape of grooves, angles of their orientation, surface roughness, deformation depth and surface cleanliness). Thus, it can be assumed that the cylinder liner material and the topography of the lining surface are the basic functional features of the sleeve and thus the technological parameters for these features can be determined (Fig. 1).

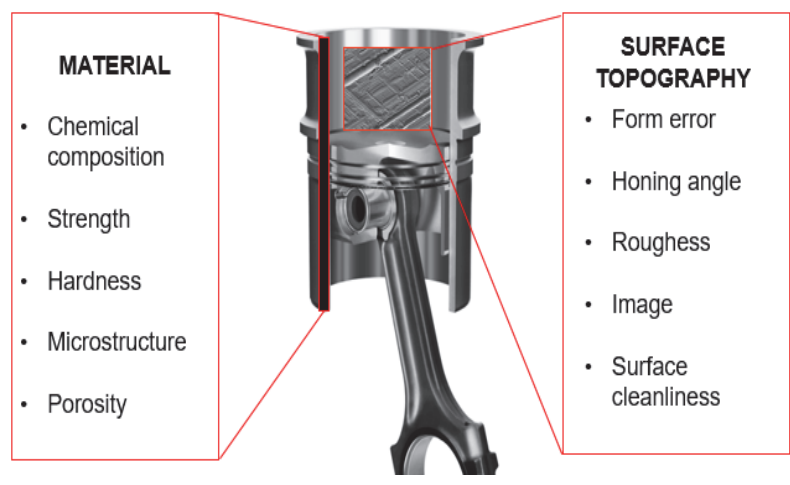

Fig. 1. Functional characteristics of the cylinder liners in the system PRC [15].

The current global scale development of propulsion systems is based on the conventional SI and CI piston engine technology, which have undergone extensive technological development in recent years. With regard to cylinder liners, the current development tendencies are primarily directed towards the sleeve material, mainly relating to the increase of the ad hoc tensile strength due to an increase in maximum combustion pressures exceeding $P_{\max }$ of 23-25 MPa (Heavy Duty Diesel Engines), which require materials with a strength rating of $R_{m}>300 \mathrm{MPa}$ [11-15].

New materials, aside from the transfer of increased thermal-mechanical loads and good thermal conductivity, should meet the following requirements:

* Corresponding author: jozef.gruszka@put.poznan.pl 
- cylinder top opening macro and micro geometry stability,

- ability to reduce friction loss,

- high friction, abrasion and corrosion resistance (EGR system) and no scratching tendency,

- good vibration damping ability and associated resistance to cavitation,

- overall weight reduction.

The whole solution should have a significant impact on meeting the environmental requirements for reducing oil consumption and particle emissions at economically justified manufacturing costs $[1,2,14]$.

\section{Directions of changes in cylinder liners casting shape}

The basic construction material used for cylinder liners is still the gray cast iron alloy with flake graphite in a pearlite matrix, mainly due to its structural and tribological properties:

- good strength and fatigue resistance at room temperature and at elevated temperatures (such as EN-GJL-250 tensile strength $R_{m}=250-300 \mathrm{MPa}$, at $400{ }^{\circ} \mathrm{C}$ ),

- modulus of elasticity $E=100-120 \mathrm{GPa}$,

- good thermal expansion $\alpha=10-12\left(20-200{ }^{\circ} \mathrm{C}\right) 10^{-6}$ $\mathrm{K}^{-1}$,

- high thermal conductivity $\lambda=47\left(20^{\circ} \mathrm{C}\right) \mathrm{W} \cdot \mathrm{m}^{-1} \mathrm{~K}^{-1}$,

- wear resistance (abrasive, corrosive and cavitation),

- no scratching tendency,

- good vibration damping ability [1, 7, 15-17].

In addition, cast iron alloy with pearlite matrix flake graphite has good casting properties (mold filling ability), machinability, and the possibility of material recovery in the machining process (closed material circulation and relatively low manufacturing costs). It is also a structural material used for cylinder blocks similarly to aluminum alloys (Tab. 1).

Table 1. Comparison of basic properties of cast iron for cylinder blocks and cylinder liners [1, 14].

\begin{tabular}{|c|c|c|c|c|c|c|c|}
\hline \multirow[b]{2}{*}{ Properties } & \multirow[b]{2}{*}{ Unit } & \multicolumn{6}{|c|}{ Material property } \\
\hline & & A 390 & $\begin{array}{c}\text { EN-GJL } \\
250\end{array}$ & $\begin{array}{c}\text { EN-GJL } \\
300\end{array}$ & \begin{tabular}{|c|} 
EN-GJV \\
450
\end{tabular} & $\begin{array}{c}\text { EN-GJS } \\
600\end{array}$ & $42 \mathrm{CrMo}$ \\
\hline $\begin{array}{l}\text { Tensile } \\
\text { strength Rm }\end{array}$ & $\mathrm{MPa}$ & 275 & 250 & $300-375$ & $450-525$ & $>600$ & $900-1150$ \\
\hline $\begin{array}{l}\text { Elastic } \\
\text { modulus Eo }\end{array}$ & GPa & 80 & 105 & 115 & 145 & 170 & 210 \\
\hline $\begin{array}{l}\text { Elongation at } \\
\text { break point } \\
\text { Amin }\end{array}$ & $\%$ & 1 & 1,5 & 1,5 & 1,0 & 0,5 & (10) \\
\hline $\begin{array}{l}\text { Fatigue } \\
\text { strength } \\
\left(20^{\circ}-225^{\circ} \mathrm{C}\right)\end{array}$ & MPa & $100-35$ & $110-100$ & $125-120$ & $210-205$ & - & $(280)$ \\
\hline $\begin{array}{l}\text { Thermal } \\
\text { conductivity } \\
\lambda\left(20^{\circ} \mathrm{C}\right)\end{array}$ & $\mathrm{W} \cdot \mathrm{m}^{-1} \mathrm{~K}^{-1}$ & 130 & \multicolumn{2}{|c|}{ 33-34 } & $30-37$ & $28-35$ & (50) \\
\hline $\begin{array}{l}\text { Thermal } \\
\text { expansion } \\
\alpha\left(20^{\circ}-200^{\circ} \mathrm{C}\right)\end{array}$ & $10^{-6} \mathrm{~K}^{-1}$ & 18 & \multicolumn{2}{|c|}{12,5} & 12,3 & 12 & $11-12$ \\
\hline Density & $\mathrm{g} / \mathrm{cm}^{3}$ & $2,6-2,7$ & \multicolumn{4}{|c|}{$7,1-7,3$} & 7,7 \\
\hline Hardness & $\mathrm{HB}$ & $110-150$ & $260-$ & 310 & $260-310$ & $280-330$ & 240 \\
\hline Structure & & & \multicolumn{4}{|c|}{ Pearlitic with ferrite } & $\begin{array}{l}\text { Marten- } \\
\text { sitic }\end{array}$ \\
\hline Graphite form & & & Fla & & Vermicular & Ball & \\
\hline $\begin{array}{l}\text { Technological } \\
\text { process }\end{array}$ & & Casting & \multicolumn{4}{|c|}{ Centrifugal casting } & Forging \\
\hline $\begin{array}{l}\text { Material } \\
\text { availability }\end{array}$ & & \multicolumn{2}{|c|}{$\begin{array}{c}\text { Base materials in } \\
\text { production }\end{array}$} & \multicolumn{4}{|c|}{ Developing materials partly in production } \\
\hline
\end{tabular}

Research and analysis of new cast iron groups based on available literature data $[1,2,15-17]$, cylinder liner manufacturers findings (FM, GKN and MAHLE) as well as own research in [14] have shown that new construction materials in order to meet the increased requirements of tensile strength limit $\left(R_{m}>300 \mathrm{MPa}\right)$ belong to the cast iron group:

- with flake graphite (EN-GJL 300),

- with vermicular graphite (EN-GJV 450),

- cast iron with ball graphite (EN-GJS 600),

whose basic properties are listed in Table 1 against the background materials used for cylinder blocks and cylinder liner castings?

As a result of the castings investigated by means of centrifugal casting from standard cast iron previously used for cylinder liners (EN-GJL-250) and cast iron castings with alloy elements (EN-GJL-300) and ductile cast iron (EN-GJV 450 and EN-GJS 600) the following results were obtained (Table 2):

- cast iron with addition of $\mathrm{Mo}$ and $\mathrm{Cu}$ alloys in relation to standard cast iron was mainly characterized by an increase in the Mo proportion from $0.16 \%$ to $0.4-0.5 \%$ and a $\mathrm{Cu}$ fraction of $0.75 \%$, which allows for the tensile strength of $R_{m}>300$ $\mathrm{MPa}$. In the tested castings the minimum tensile strength was $R_{m}=320 \mathrm{MPa}$ at hardness of $250 \mathrm{HBW}$. The arrangement of graphite and the matrix was similar to that of standard pearlite cast iron;

- cast iron with an addition of $\mathrm{N}(0.016 \%)$ was characterized by a reduced $\mathrm{P}(0.27 \%), \mathrm{S}(0.01 \%)$, Mo $(0.05 \%)$ and $\mathrm{Ni}(0.04 \%)$ but increased $\mathrm{Cu}(0,80 \%)$. The minimum tensile strength was $R_{m}=347 \mathrm{MPa}$ and hardness was $265 \mathrm{HBW}$. A significant change in the microstructure arrangement is the shape of the graphite, which has a changed size with the unmodified pearlite matrix compared to the standard cast iron matrix;

- cast iron with vermicular graphite is gaining in importance especially through the beneficial combination of mechanical, physical and technological properties. The properties of this cast iron lie between the properties of flake graphite and ball graphite, as illustrated in Tab. 1.

An important feature of this cast iron is that, with well-developed vermiculite grafts, material properties do not depend significantly on machining processes [16]. The problem is, the dependence of the structure and properties of the cast iron on the wall thickness and the cooling rate. In this relation, the behavior of this cast iron is similar to cast iron with flake graphite $[17,18]$.

The successful development of the cylindrical liner molding technology in the centrifugal casting process has led to the development of a series of new cast iron production programs involving $\mathrm{Mo}, \mathrm{Cu}$ and $\mathrm{N}$ as well as $\mathrm{Mg}$. Cast iron with $\mathrm{Mo}, \mathrm{Cu}$ and $\mathrm{N}$ mainly as materials for cylinder liners for HDD motors (DAF, VOLVO, Daimler AG and Track). In turn, cast iron with vermicular graphite (Mg modifier) found use in Europe, Asia and the Americas mainly as a material for cylinder blocks of engines (reduction of wall thickness and weight reduction) with a displacement of $1.6-14.6 \mathrm{dm}^{3}$ 
HD type (Audi Ford, Hyundai, John Deere, MAN, Daimler Trucks, Renault) and HDD type (Caterpillar, VOVO, DAF) [16].

Table 2. Comparison of cast iron properties tested.

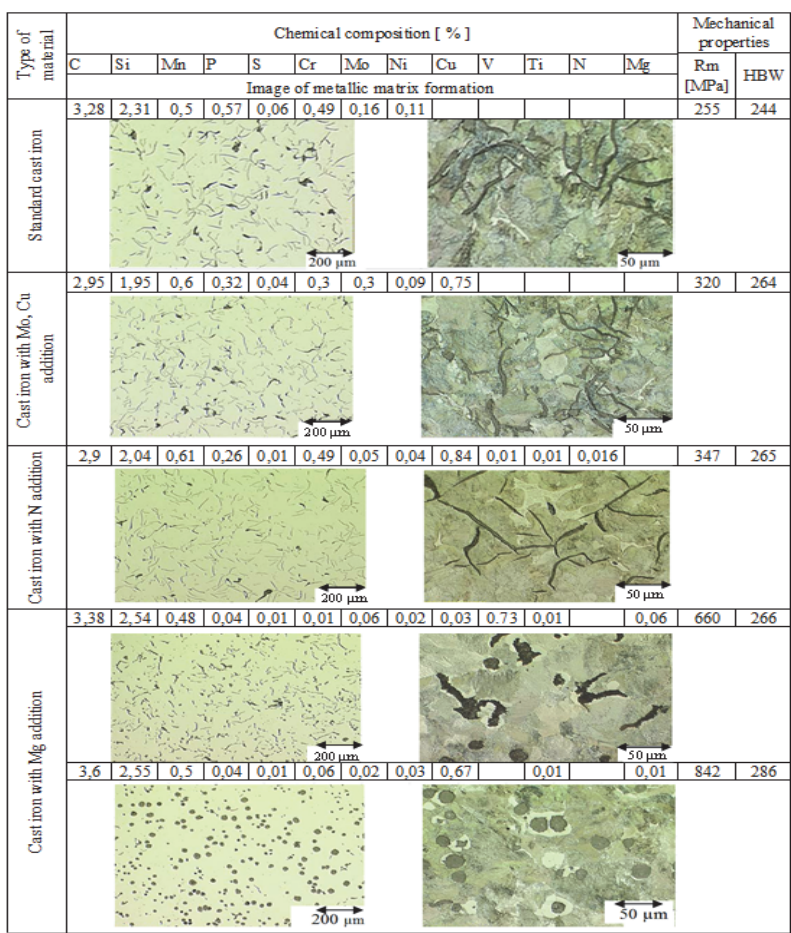

In recent literature, many of the results of studies on flake, vermicular and ballistic graphite in cast iron, presented currently have been subjected to an isothermal transformation quenching process, which are referred to as cast iron types:

- ADI - Austempered Ductile Iron (spheroidal ductile iron tempered with isothermal conversion),

- DADI - Direct Austempered Ductile Iron (spheroidal cast iron subjected to direct tempering with isothermal conversion),

- AADI - AsformingAustempered Ductile Iron (spheroidal cast iron tempered with isothermal transformation under low temperature heat-plastic treatment),

- AVCI - Austempered Vermicular Cast Iron (cast iron with vermicular graphite tempered with isothermal conversion),

- AGI - Austempered Gray Iron (cast iron with flake graphite tempered with isothermal conversion) [17].

The use of isothermal tempering allows the cast iron to have exceptionally good strength and durability characteristics, with exceptional abrasion resistance and less than $10 \%$ density compared to steel or cast steel [2, 17]. Significant barriers to the serial application of this type of a solution are the manufacturing costs (significant costs of isothermal tempering followed by machining costs) [14].

\section{The directions of changes in shaping the topology of the liner opening surface after the finishing process}

The final shape of the cylinder opening surface geometry is formed in the finishing process. Over the last dozen or so years, this process has been the subject of intensive development mainly due to:

- development of the finishing machinery and moving from single-stage finishing machines to multi-stage finishing with the ability to automate the finish process and scanning for shape errors and its correction in the process along with the possibility of surface roughness and SPC analysis,

- ability to remove traces of previous conventional treatment (roughness, reinforcements and surface tension),

- cutting tools with high durability, homogeneous crystal structure, and self-sharpening diamond tips (ND, MD) and $\mathrm{SiC}$ carborundum cutting tips, cubitron (SGG) and Norton Quantum (NQD),

- possibility of using lasers, as a technological tool in the process of honing (cutting of cracks in the form of micro oil trays, laser ablation, thermal spray coating),

- development of techniques used in surface topography (contact measurements, optical, scanning microscopy), increase in instrument range (resolution, various filters and speeds, 2D and 3D measurements),

- the size and shape of the oil reservoirs in the laserforming TDC zone,

- $\quad$ surfacecleanliness [11-15, 18, 19].

The availability of many technological variants of the finishing process has enabled cylinder liner manufacturers to carry out optimization work on new engine designs, in terms of:

- macro structure of the opening shape with shape error parameters (straightness and roundness or concentricity) at the level of $<6-10 \mu \mathrm{m}$,

- shaping the surface micro geometry of the surface with roughness parameters $R_{p k}$ and $R_{k} \rightarrow 0 \mu \mathrm{m}, R_{v k}$ according to the engine design requirements $(5-15$ $\mu \mathrm{m}$ ) the honing angle $\alpha=50-140^{\circ}$ and the shape and arrangement of the cracks,

- the size and shape of the oil reservoirs in the laserguided TDC zone,

- $\quad$ surface cleanness after the finishing process [14]. In the new solutions, the formation of the cylindrical surface topography is a trend towards the method of multi-step finishing, taking into account the dependence of the $R_{k}$ parameter on the exhaust emission standard, as illustrated in the data presented in Fig. 2. Examples of the shape study of crests, vertices, recesses and surfaces between the grooves are summarized in the form surface profilography (Fig. 3) and scanning microscopy images (Fig. 4, 5).

From the data in Figure 2, the decrease of the average values of the parameters $R_{p k}(0.27 \mu \mathrm{m}$ to $0.13 \mu \mathrm{m})$ $R_{k}$ (from $1.08 \mu \mathrm{m}$ to $0.41 \mu \mathrm{m}$ ) and the $R_{v k}$ groove depth 
reduction (from $2.05 \mu \mathrm{m}$ to $1.4 \mu \mathrm{m}$ ) can be observed with the increase of emissions requirements from Euro III to Euro V.

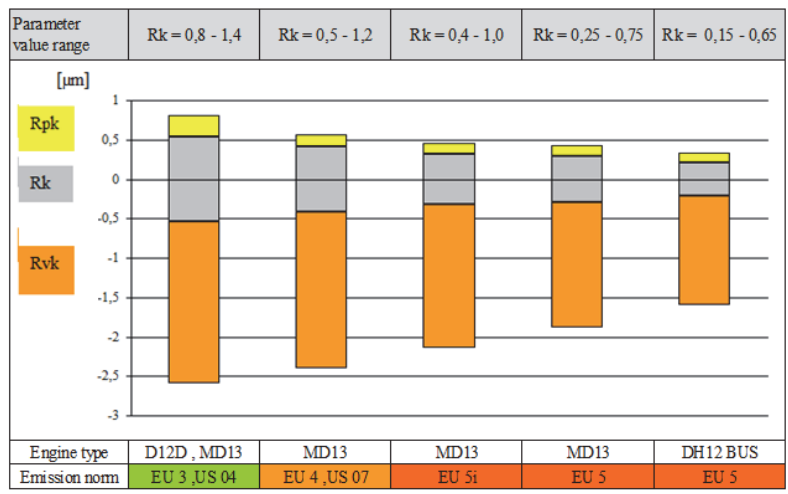

Fig. 2. Cylinder liners surface roughness parameters test results according to the purpose of the liner for the VOLVO HDEP type of engine $[1,14]$.

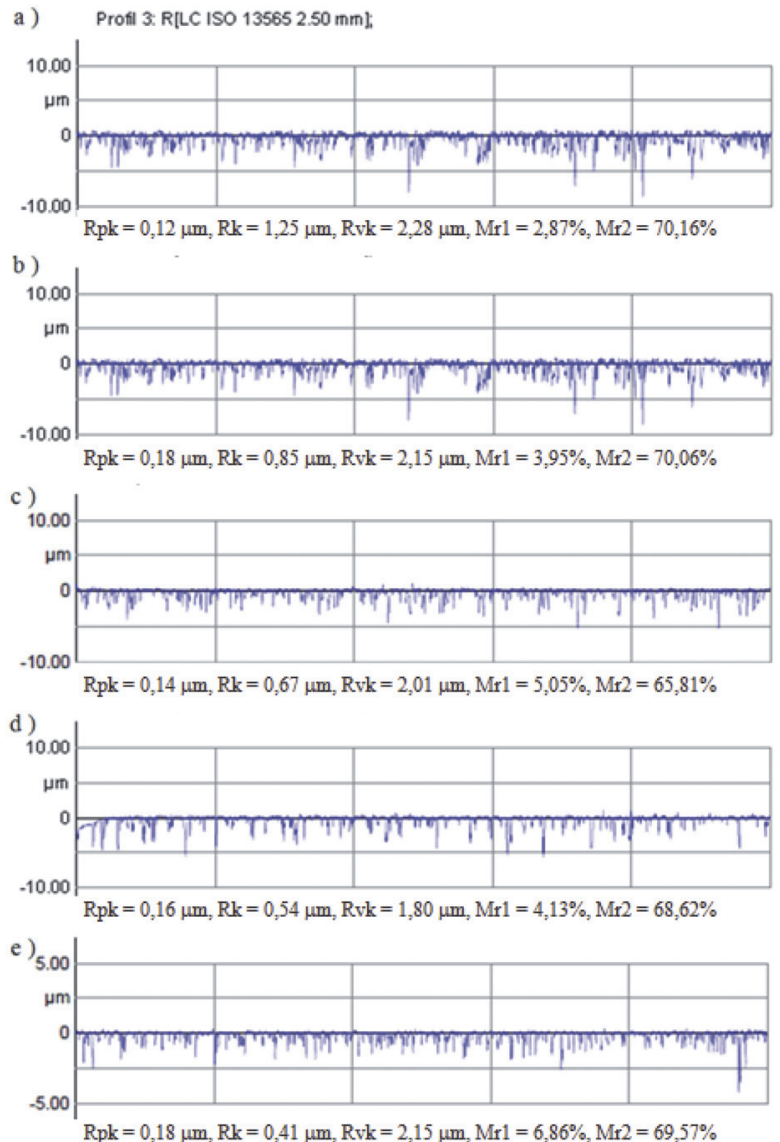

Fig. 3. Examples of surface profilographs after standard plateau finishing method (a) and smooth finishing method (b-e) depending on the range of parameter $R_{k}$.

The results of examining the images of the structure of vertices, recesses and surfaces between grooves by scanning electron microscopy (Fig. 4, 5) were the basis for determining the surface deformation levels as a result of the finishing process and determining levels of qualification for permissible and unacceptable surface images (VOLVO) [2, 14].

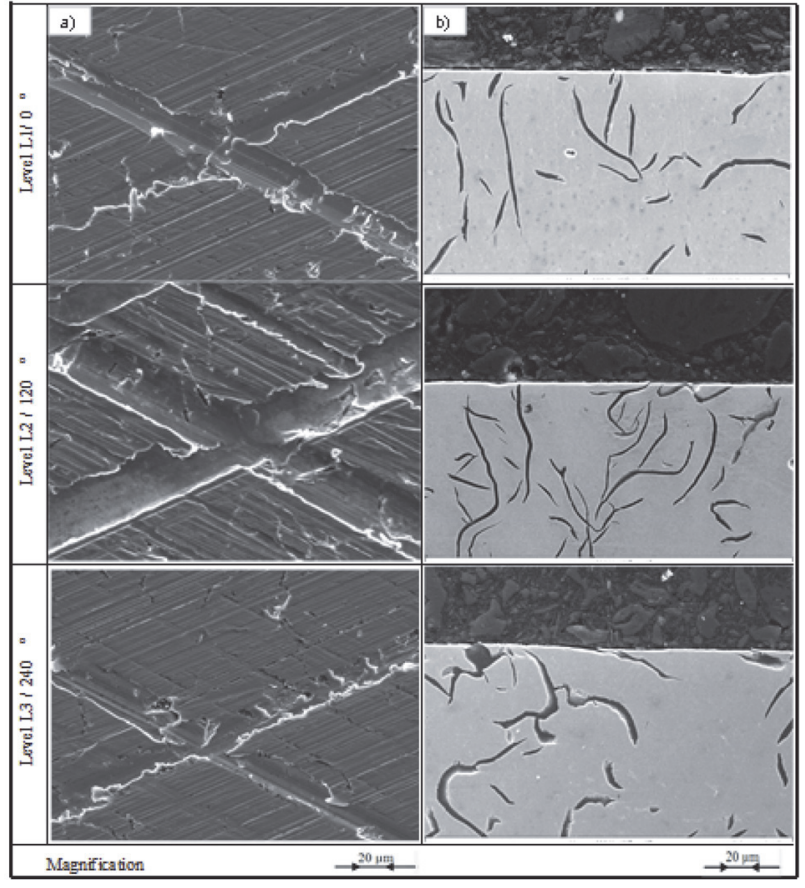

Fig. 4. Surface topography images (a) and surface layer deformation images (b) after standard finishing using SEM imaging.

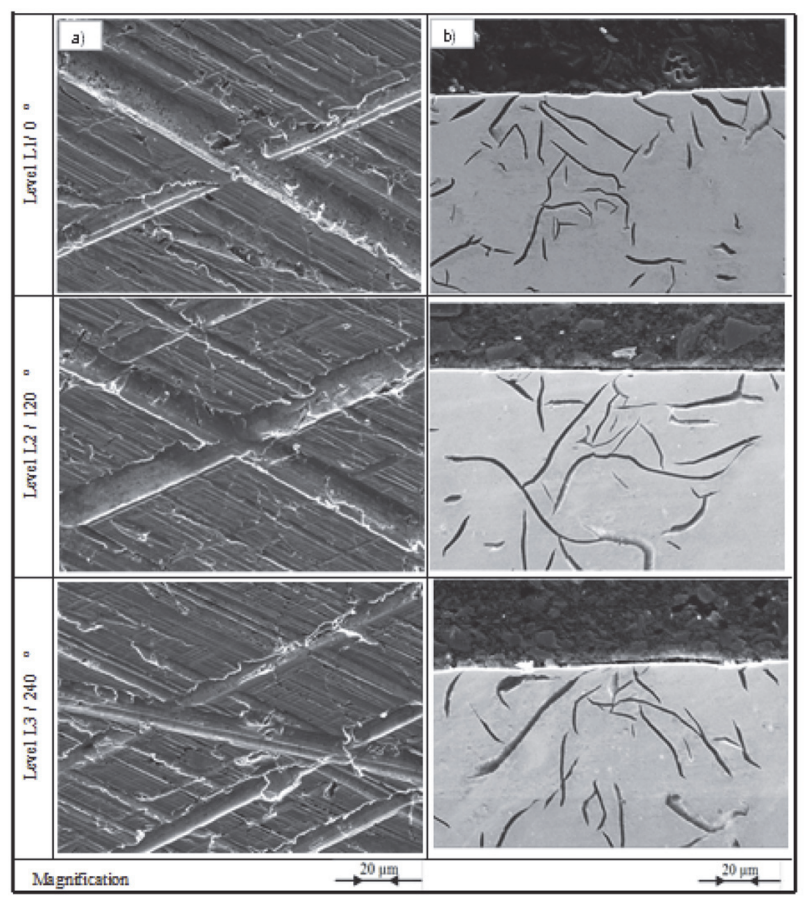

Fig. 5. Surface topography images (a) and surface layer deformation images (b) after smooth finishing using SEM imaging.

The use of white light interferometry (WLI) is new in surface metrology. Studies [19-21] have shown the possibility of wide applications for this method in spatial 3D surface roughness measurement including cylinder liner surface [1]. So far in industrial practice, the methodology of contact measurements in the 2D parameter system $\left(R_{p k}, R_{k}\right.$ and $R_{v k}, M_{r 1}$ and $\left.M_{r 2}\right)$ is used to evaluate the topography of the liner surface. In 
industrial conditions, the method of contact measurement in $3 \mathrm{D}$ was very rare. Measurements require highly qualified personnel in the field of 3D parameters and related software (TalyMap-Form Talysurf Series 2 from Taylor Hobson) [20]. The problem of the lack of industrial use of 3D parameters is also due to the lack of formalized parameter ranges with respect to the topography of the finish and their influence on, for example, the functional properties of the surface. For 2D parameters, the $R_{p k}$ parameter defines the bearing surface area for the piston rings), the $R_{k}$ parameter defines the effective surface area and the $R_{v k}$ parameter describes the surface area of the oil retention.

Figure 6 shows an example of an image analysis of a cylinder liner surface topography based on the MBN 37800-1 (Mercedes Benz Norm) using the WLICyl-S white light interferometer (WLI) (WLICyl-S measurement station for honing structures by the BMT company) [21].
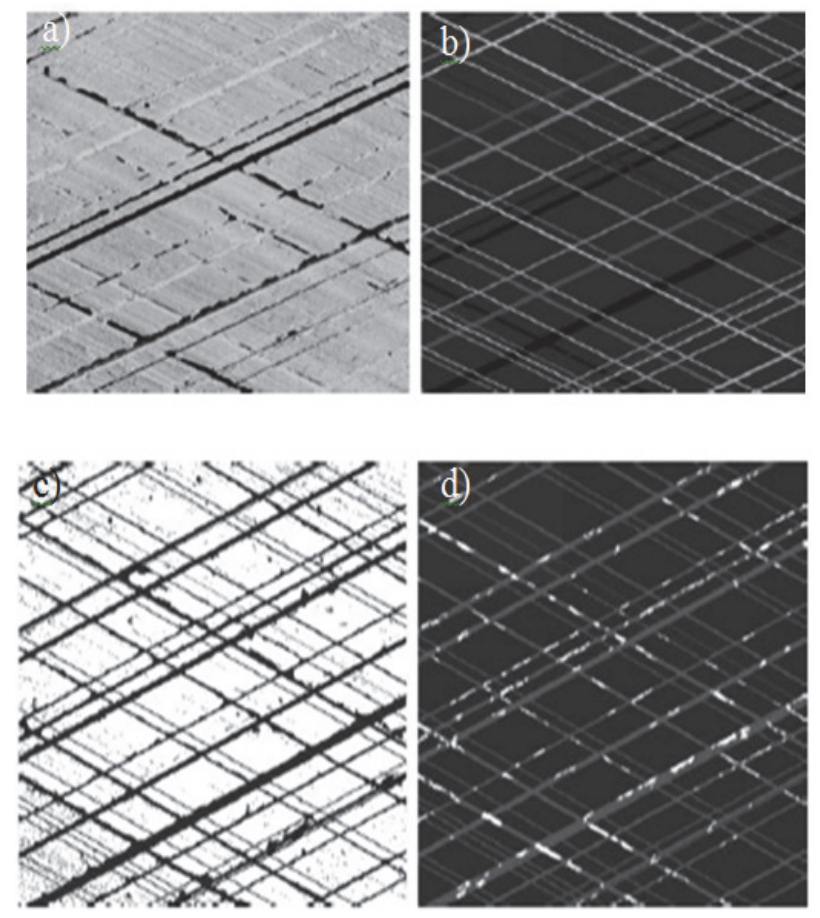

Fig. 6. Honing structure according to MBN 37800-1. From left (a) to right (d): original topography after the F-operator application, raster image, contact surface (white), undesired surface structures on the sheet metal part (white) [13].

The MBN 37800-1 specifies tolerance limits, measurement and evaluation conditions, and the distribution of measurement points in both $2 \mathrm{D}\left(R_{p k}, R_{k}\right.$ and $R_{v k}$ ) and 3D layouts with a range of parameters and determines tolerable casting errors in the porosity range on the finish. When using the WLICyl measuring instrument, it is necessary to have a license to use MBN 37800-1. According to many publications [19-21], the use of scanning white light interferometry will require a lot of research into new test methods or an international comparative research initiative (round-robin), for example, when measuring Talysurf CCI 600 [20] and WLICyl-Swith the use of the MBN 37800-1 standard or the proposed standard ISO/DIS 25178.

\section{Conclusions}

Compliance with the new design requirements of the type HDD/HDEP internal combustion engines (increase of maximum combustion pressures exceeding $P_{\max }=$ $=23-25 \mathrm{MPa}$ ) requires the construction of cylinder liners that can meet the strict criteria of material strength $\left(R_{m}>300 \mathrm{MPa}\right)$ and the surface topography to meet the requirements of standards related to reduction of oil consumption and particulate emissions.

The cylinder liner material and topography of the liner surface are the basic functional features of the cylinder in the PRC system of an internal combustion engine and thus the technological parameters for each feature can be determined, which in turn define the key criteria for selecting the manufacturing technology.

The current development of the cylinder liner molding technology in the centrifugal casting process allows for the production of series of new cast irons with $\mathrm{Mo}, \mathrm{Cu}$ and $\mathrm{N}$ as well as $\mathrm{Mg}$ additions. The use of new cast iron grades requires a production cost analysis from the foundry which is due to the share of alloyed material in relation to the base materials.

In the process of forming the surface of the top opening in the size range $(<6-10 \mu \mathrm{m})$ and micro geometry of the cylinder liner surface the smooth multiprocess finishing technique seems prevalent. Smooth finishing technology allows the topography of the surface to be adjusted in 2D parametric and 3D surface configurations to meet oil consumption and particulate emissions standards.

New methods of optical 3D measurements (WLI) using the MBN 37800-1 standard will requirethe implementation of research methodology and international benchmarking and comparative studies with the round-robin method based on the instrument used (Talysurf CCI 600 or WLICyl-S).

\section{References}

1. Technical information from meetings MAHLE VOLVO, DAF, MAN, PSA-BMW, Unpublished material (Krotoszyn, 2005-2010)

2. Zylinderkomponenten, Eigenschaften, Anwendungen, Werkstoffe MAHLE (Stuttgart, 2009)

3. W. Karpiuk, T. Borowczyk, M. Idzior, R. Smolec, 2016 International Conference on Sustainable Energy, Environment and Information Engineering, 16-22 (2016)

4. W. Karpiuk, R. Smolec, M. Idzior, 2016 International Conference on Sustainable Energy, Environment and Information Engineering, 37-43 (2016)

5. G.M. Szymanski, F. Tomaszewski, Mechanical Systems and Signal Processing 68-69, 479-490 (2016), DOI: 10.1016/j.ymssp.2015.07.015

6. J. Merkisz, M. Idzior, P. Lijewski, P. Fuc, W. Karpiuk, Proceedings of the Ninth Asia-Pacific International Symposium on Combustion and Energy Utilization 352-356 (2008) 
7. P. Fuc, P. Kurczewski, A. Lewandowska, E. Nowak, J. Selech, A. Ziolkowski, International Journal of Life Cycle Assessment 21, 1438-1451 (2016), DOI: 10.1007/s11367-016-1104-y

8. J. Merkisz, M. Idzior, J. Pielecha, W. Gis, WIT Transactions on the Built Environment 111, 181-189 (2010), DOI: 10.2495/UT100171

9. Z. Stelmasiak, D. Pietras, IOP Conference SeriesMaterials Science and Engineering 148, UNSP $012087 \quad$ (2016), DOI: $\quad 10.1088 / 1757$ $899 X / 148 / 1 / 012087$

10. S. Carras, J. Gruszka, T.G. Mathia, D. Mazuyer, FP. Ninove, P. Pawlus, 10th International Symposium on Measurement and Quality (Osaka, 2010)

11. J. Gruszka, A. Suchecki, Silniki Spalinowe 3, 16-26 (2007)

12. J. Gruszka, Inżynieria Maszyn 12, 42-53 (2009)

13. J. Gruszka, Archiwum Technologii Maszyn i Automatyzacji 30, 73-78 (2010)

14. J. Gruszka, Silniki Spalinowe 2009-SC1-157, 350357 (2009)

15. J. Gruszka, Technologiczne ksztattowanie cech funkcjonalnych warstwy powierzchniowej tulei cylindrowych (Poznan 2012)

16. S. Dawson, $68^{\text {th }}$ WFC - World Foundry Congress, 93-99 (2008)

17. E. Guzik, Archiwum Odlewnictwa, 29-85 (2001)

18. W.L. Guesser, T. Fundições, P.V. Duran, W. Krause, Congres Le diesel, 11 (2004)

19. NAGEL: Honsymposium (2009)

20. C. Łukianowicz, PAK 56, 1055-1058 (2010)

21. J. Seewig, C. Wiehr, S. Groger, Charakterisierung technischer Bauteiloberflachen - Stand der Oberflachenmesstechnikheute (ak-rauheit.de, 2017) 